\title{
Apolipoprotein B Measurement
}

National Cancer Institute

\section{Source}

National Cancer Institute. Apolipoprotein B Measurement. NCI Thesaurus. Code C74734.

The determination of the amount of apolipoprotein B present in a sample. 